\title{
Detection of Candida albicans in the screening of cervical cancer in rural population of Lucknow
}

\author{
Misra Jata S1 $1^{1}$, SrivastavaAnand $N^{2}$, Zaidi Zeeshan $H^{3}$, Singh Shivani4 ${ }^{4}$,
}

\begin{abstract}
${ }^{1}$ Cytologist, Department of Pathology, Era’s Lucknow Medical College and Hospital, Era University, Lucknow, Uttar Pradesh, India

${ }^{2}$ Director Research, Era's Lucknow Medical College and Hospital, Era University, Lucknow, Uttar Pradesh, India ${ }^{3}$ Assist Professor, Department of Community Medicine, Era’s Lucknow Medical College and Hospital, Era University, Lucknow, Uttar Pradesh, India.

${ }^{4}$ Research Assistant, Department of Pathology, Era’s Lucknow Medical College and Hospital, Era University, Lucknow, Uttar Pradesh, India
\end{abstract}

\begin{abstract}
Background: Candida infection study is essential in rural women who are illiterate and financially weak and are not aware of personal genital hygiene, and thus harbor persistent vaginal infections due to insufficient medical amenities. Method: Rural cervical cancer screening has been in progress in the western region of Lucknow, India, since May 2013 through camp approach, and to date, a total of 2949 women have been cytologically examined. The candidal infection has been observed in the 143 cervical smears of women, and findings have been analyzed concerning the different predisposing factors of cervical carcinogenesis. Result: The incidence of Candida albicans seen in cervical smears of the total 2949 women examined was $4.8 \%$ higher than in their urban counterparts $(1.2 \%)$. The Candida was seen more in the inflammatory smears $(9.4 \%)$ and those showing squamous intra-epithelial lesions of the cervix (SIL). $-(8.2 \%)$. The fungus was found more prevalent in the reproductive age group and women complaining of vaginal discharge and resulted from persistent vaginal infections in the rural women that should be treated. The Candida was commonly seen in erosion cervix cases, but it was high in women with cervicitis and cervix bleeds on touch. Conclusions: This persistent vaginal infection was seen in illiterate and impoverished rural women who were unaware of personal genital hygiene. There is a need to create awareness for personal genital hygiene through health workers for making any cancer screening program meaningful and successful.
\end{abstract}

KEYWORDS: Candidal infection; Reproductive age; Vaginal discharge; Erosion cervix; Inflammatory smears.

\section{INTRODUCTION}

$\mathrm{C}$ andida albicans is the most critical fungal opportunistic pathogen residing as a commensal in the genitourinary tract and other body parts[1]. This fungus is common inhabiting the lower female genital flora, and its hyphae and spores are easily discernible during the screening of cervicovaginal smears for early detection of carcinoma cervix. Its infection is more prevalent in rural women who being illiterate and impoverished, are not aware of personal genital hygiene. Consequently, vaginal infection is widespread in rural women, which remains persisted due to not being detected and treated because of a lack of medical amenities[2] [3]. Rural cervical cancer screening has been in progress since May 2013 through the camp approach, and to date, a total of 2949 women have been cytologically examined from 5862 women attending the camps. In the present communication, the number of $\mathrm{C}$. albicans detected in the cervical smear's of 2949 women

Correspondence: Dr. J. S. Misra, Cytologist, Department of Pathology, Era’s Lucknow, Medical College and Hospital, Era University, Lucknow, India. Email: jata misra@yahoo.com

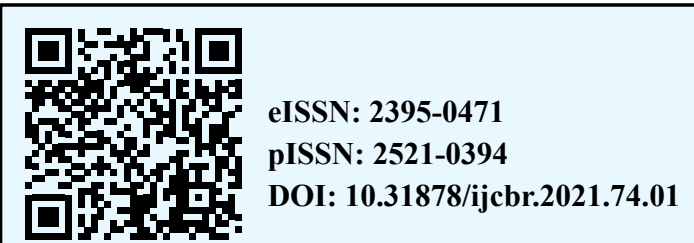

(C) Authors; 2021. (CC BY-NC-SA 4.0)

This is an Open Access article which permits unrestricted non-commercial use, provided the original work is properly cited. 
has been investigated in detail concerning the different predisposing factors of cervical carcinogenesis.

\section{Material And Methodology Study design: A descriptive study}

Ethical approval: TEthical Clearance was obtained from the Ethical Committee of the Institute for initiating the rural cervical cancer screening program.

Inclusion criteria: Age above 18 years both perimenopausal and post-menopausal women

Exclusion criteria: Pregnant women and those undergone hysterectomy.

Locus of the study: Era's Lucknow Medical College and Hospital, Era University, Lucknow

Sampling method: Consecutive sampling

Sample size: Cervical smears have been examined in 2949 women from a total of 186 camps organized between May 2013 till date.

\section{Methodology:}

In each case, a scrape smear was collected by the gynecologist attending the camp from the squamocolumnar of the cervix and immediately fixed in absolute alcohol. The cervical smears were sent to the Cytology lab of the Pathology Department of the College, where they were stained according to Papanicaou's technique. The cytopathological findings seen in the cervical smears were graded according to the revised Bethesda system of Classification of 2014[4]. Candidal infections were diagnosed in cervical smears by organisms either in the form of hyphae or spores of the fungus. The informed consent was obtained from the women who have undergone Pap smear examination on the Pap smear form in the form of thumb impression if illiterate and signature if literate.

The incidence of $\mathrm{C}$. albicans was studied under different pathological conditions of the cervix, and different risk factors of cervical cancer were studied in detail, such as age, gynecological symptoms including infertility, clinical lesions of the cervix, and lastly, illiteracy. Data analysis: the collected data were statistically analyzed using the chi-square test using software SPSS version 22 .

\section{RESUlts}

Candida albicans were diagnosed mainly in spores in 143 out of 2949 women whose cervical smears were examined (4.8\%)- Figure-1 This incidence observed in rural women is relatively high than $1.2 \%$ seen in the urban population of Lucknow. Out of the 143 cases of Candida, 128 cases were seen in the initial smears $(89.5 \%)$, while the remaining 15 were found during follow- up of precancerous lesions of the cervix $(10.5 \%)$.

The distribution of 143 cases of Candida according to the cytology status in 2949 women was found to be as follows-

SIL - 498 cases detected - number showing Candida- 41(8.2\%)

ASCUS - 234 cases detected - number showing Candida - 3(1.2\%)

Inflammation - 951 cases detected - number showing Candida - 99(9.4\%)

The difference in the incidence of Candida in SIL and inflammatory cases were found to be statistically significant from that observed in ASCUS cases $\left(X^{2}=13.61 ; p=0.0002\right)$. The association of a fungus with inflammation may be due to persistent vaginal infection seen in rural women who are mostly illiterate. Illiteracy was seen in 1780 women of 2949 women examined, and Candida was seen in 92 of them $(5.1 \%)$. The remaining 1169 women were literate, and Candida was seen in 51 of them $(4.3 \%)$. However, the difference in the incidence of Candida between the two groups was statistically insignificant $\left(\mathrm{X}^{2}=0.993 ; \mathrm{p}=0.319\right)$. Here, it should be emphasized that $90 \%$ of the literate women had only primary education and could sign in Hindi, and only the remaining $10 \%$ had secondary education. A high incidence of illiteracy may cause poor genital hygiene, resulting in the association of fungus in many inflammatory and SIL cases. However, it was interesting to note that only 2 of the SIL cases showing Candida were of high grade (HSIL).

The distribution of 143 cases of Candida seen in the cervical smear was analyzed in different age groups (Table-1).

\section{Table 1. Relation of Candida with age}

\begin{tabular}{|l|l|l|}
\hline Age group & $\begin{array}{l}\text { No. of women } \\
\text { examined }\end{array}$ & $\begin{array}{l}\text { No. of Candida } \\
\text { detected }(\%)\end{array}$ \\
\hline$<20$ years & 117 & $6(5.1 \%)$ \\
\hline $21-30$ years & 1163 & $63(5.4 \%)$ \\
\hline $31-40$ years & 973 & $60(6.1 \%)$ \\
\hline$>40$ years & 696 & $14(2.1 \%)$ \\
\hline
\end{tabular}

The candidal infection was more prevalent in the reproductive age group than in the postmenopausal women above 40 years $(2.1 \%)$. The candidal infection was maximum in the middle age group of $31-40$ years $(6.1 \%)$, followed by young women between 21 and 30 years (5.4\%) and $5.1 \%$ in the young girls below 20 years. The difference in the incidence of Candida between reproductive and post-menopausal women was found to be statistically significant $\left(\mathrm{X}^{2}=266.9\right.$; $\mathrm{p}<0.001)$.

The gynecological symptoms complained by

Int. j. clin. biomed. res. 2021;7(4):1-5 
2949 women of the study and the number of Candida detected with each symptom are shown in Table-2.

\section{Table 2. Relation of candidal infection with gynaecological symptoms}

\begin{tabular}{|l|c|c|}
\hline \multicolumn{1}{|c|}{$\begin{array}{c}\text { Gynaecological } \\
\text { symptoms }\end{array}$} & \multicolumn{2}{|c|}{ No of cases } \\
\cline { 2 - 3 } & $\begin{array}{c}\text { Screened } \\
\text { cases } \\
(2949)\end{array}$ & $\begin{array}{c}\text { Showing } \\
\text { Candida } \\
(143)\end{array}$ \\
\hline $\begin{array}{l}\text { Persistent vaginal } \\
\text { discharge (Many 5-7 } \\
\text { years) }\end{array}$ & $1132(38.4)$ & $107(9.4)$ \\
\hline $\begin{array}{l}\text { Pain in lower } \\
\text { abdomen }\end{array}$ & $755(25.6)$ & $23(31)$ \\
\hline Menstrual disorder & $322(10.9 \%)$ & $13(4.1)$ \\
\hline
\end{tabular}

Table 3. Relation of candidal infection with clinical lesions of the cervix

\begin{tabular}{|l|c|c|}
\hline Cervical lesions & $\begin{array}{c}\text { No. of } \\
\text { women } \\
\text { showing } \\
\text { cervical } \\
\text { lesions }\end{array}$ & $\begin{array}{c}\text { No. and } \\
\text { percentage } \\
\text { of cases } \\
\text { showing } \\
\text { Candida }\end{array}$ \\
\hline Erosion cervix & 227 & $18(7.9 \%)$ \\
\hline $\begin{array}{l}\text { Hypertrophied } \\
\text { cervix }\end{array}$ & 61 & $3(4.9 \%)$ \\
\hline $\begin{array}{l}\text { Cervix Bleeds } \\
\text { on touch }\end{array}$ & 22 & $2(9.1 \%)$ \\
\hline Cervicitis & 3 & $1(11.1 \%)$ \\
\hline $\begin{array}{l}\text { Endocervical } \\
\text { lesions }\end{array}$ & 122 & - \\
\hline
\end{tabular}

The vaginal discharge was the most common symptom (1132 cases- 38.4\%) and was present in most women persisting even for 5-7 years. The incidence of candidal infection was $9.4 \%$ in vaginal discharge cases (107 cases). The pain in the lower abdomen was the second symptom complained by the rural women $(755-25.6 \%)$, and some of them were associated with vaginal discharge. Candida albicans was low $(3.05 \%)$, with pain in the lower abdomen. The third symptom- menstrual disorders were seen in 322 cases $(10.9 \%)$ and was often associated with pain in the lower abdomen or vaginal discharge. The candidal infection was seen in $4.1 \%$ of these cases, and no case of contact bleeding or post-menopausal bleeding was present. The statistical analysis of the incidence of Candida with these symptoms showed a significant difference between vaginal discharge and other symptoms $\left(\mathrm{X}^{2}=39.93 ; \mathrm{p}<0.001\right)$.

Primary infertility was seen in 112 women, most young girls. The candidal infection was seen in 4 of these 112 cases $(3.5 \%)$. The secondary infertility complications were seen in 24 women, and 2 of these showed candidal infection (8.3\%). The difference in the incidence of candidal infection in these two groups was statistically insignificant $\left(\mathrm{X}^{2}=1.063 ; \mathrm{p}=0.303\right)$. All these infertility cases were referred to Era's Medical College Lucknow for treatment.

Different types of clinical lesions were shown by 2949 women studied, and several candidal infections seen with these lesions are shown in Table-3. The maximum number of Candida was seen with cervicitis $(11.1 \%)$ though the cases were meager (3). It was followed by cervix bleeds on touch $(9.1 \%)$ and erosion cervix $(7.9 \%)$. Candida was seen in $4.9 \%$ of the hypertrophied cervix cases, while the endocervical lesions did not have fungus. The difference in the incidence of Candida with different lesions of the cervix was found to be statistically significant $\left(\mathrm{X}^{2}=\right.$ $14.69 ; \mathrm{p}=0.005)$.

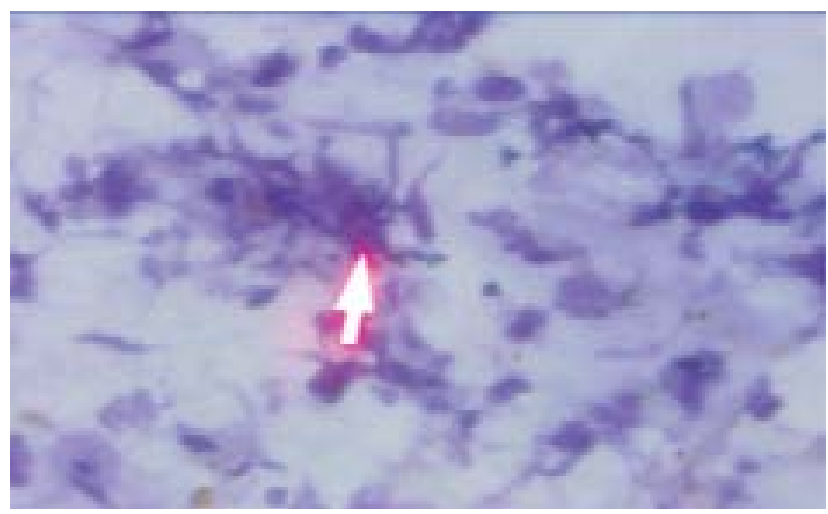

Fig 1. The cervical smear shows spores of Candida albicans along with inflammatory changes

\section{Discussion}

In the present series, C. albicans was found to be $4.8 \%$ in 2949 women studied, and this incidence was much higher than $1.2 \%$ seen in their urban counterparts of Lucknow[5]. As suggested earlier, the poor genital hygiene prevalent in illiterate and impoverished rural women may cause the high incidence of $\mathrm{C}$. albicans because of the persistent vaginal infections seen in them, which remain undetected and untreated as medical facilities are negligible. Fule, et al. have found a much greater incidence of C. albicans $(12.1 \%)$ in the rural women of Karnataka[6]. However, as seen in the present study, Bukhari, et al. have also found a low incidence of Candida (3.0\%) in Pakistan[7]. On the contrary, some authors have reported a high incidence of Candida - Barauti, et al. in Iran $(11.1 \%)$ and Guduco, et al. in Turkey[8] [9].

A high percentage of inflammatory smears were seen infected with Candida (9.4\%). It may be due to a lack of awareness in rural women regarding personal genital hygiene and associated 
persistent vaginal infections. The persistence of inflammation for a long time may lead to the development of SIL changes in the cervix, as the inflammatory changes are supposed to be precursors of the precancerous lesions of the cervix. Consequently, a high incidence of SIL was seen in rural women $(28.9 \%$ - 498 out of 2949$)$, which is much higher than the $8.4 \%$ observed in the urban population. Dalie, et al. have suggested that Candida causes protein degradation and enhances antigenic response leading to mucosal injuries and endogenous invasion[10]. They have seen that the extent of damage incurred is also determined by the inherent properties of epithelial cells, like the state of maturity. Mayer, et al. have found that in the endogenous fungal infection, tissue debris and accumulation of free radicals enhance the organism's virulence and increase the host's susceptibility[11]. Hence the association of Candida with cervical lesions may be related to the inflammatory effects.

Candidal infection was seen shared in the reproductive age group between 16 and 40 years, and minimal infection was seen with old age. There was statistically no significant difference between young girls up to 20 years, young women between 21 and 30 years, and middle-aged women between 31 and 40 years. Baraouti have also found that the overall presence of fungal infection was more significant with reproductive age.

Vaginal discharge was the most common gynecological symptom associated with candidal infection $(9.4 \%)$ in rural women. This may be because most women are illiterate, unaware of personal genital hygiene, and harbor persistent vaginal infections. Wohlmaster, et al. have also found more than $50 \%$ of vaginal discharge cases harboring Candida[12]. Other authors like Fule, et al. and Masand, et al. have reported a low incidence of Candida in vaginal discharge cases[13].

Though the erosion cervix was commonly seen in rural women and was associated with Candida in $7.9 \%$ of cases, the fungus was more common in women with cervix bleeds on touch $(9.1 \%)$ and cervicitis (11.1\%). Hence, these cervical lesions must be examined for candidal infection whenever detected on the clinical examination.

\section{Conclusion}

In the present study, candidal infection is commonly found in the reproductive age group and those complaining of vaginal discharge. Hence, sexually active women who show the persistence of vaginal discharge must be looked for the candidal infection. Further, there is a need to create awareness among rural women for maintaining personal genital hygiene, which can be easily achieved through the help of health workers to make any cancer screening program successful in rural India.

Acknowledgements: The authors thank village Heads of Kakori, Malihabad, and Mall blocks of west Lucknow for helping in organizing camps for cervical cancer screening.

Conflict of interest: There is no conflict of interest from either of the Authors.

Source of funding : The authors sincerely thank Mohsin Ali Khan, Chancellor, Era University, Lucknow, India, for financing the Rural cervical cancer screening program in an Intramural Research Project grant.

\section{REFERENCES}

1. SpampinatoC,LeonardiD.Candidainfections, causes, targets and resistance mechanism: traditional and alternative antifungal agents. BioMed Res Int. 2013;2013:1-13. doi: 10.1155/2013/204237; Article Id- 204237, 13 pages.

2. Tripathi N, Kadam YR, Dhobale RV, Gore AD. Barriers for early detection of cancer amongst Indian rural women. S Asian J Cancer. 2014;3(2):122-7. doi: 10.4103/2278330X.130449, PMID 24818108.

3. Misra JS, Srivastava AN, Gupta HP. Impact of literacy status on the cervical cancer screening in rural women of India. Investig Obstet Gynaecol Res. 2017;6:45-9.

4. NayarR, Wilbur DC. The PaptestandBethesda 2014. "The reports of my demise have been greatly exaggerated." (after a quotation from Mark Twain). Acta Cytol. 2015;59(2):121-32. doi: 10.1159/000381842, PMID 25997404.

5. Misra JS, Srivastava AN. Singh U Risk factors and strategies for control of carcinoma cervix in India: hospital based cytological screening of 35 years. Ind J Cancer. 2009;46(2):155-9.

6. Fule SR, Fule RP, Tankhiwale NS. Clinical and laboratory evidence of Trichomonas vaginalis infections among women of reproductive age in rural area. Indian $\mathrm{J}$ Med Microbiol. 2012;30(3):314-6. doi: 10.4103/02550857.99493, PMID 22885198.

7. Bukhari $\mathrm{MH}$, Majeed $\mathrm{M}$, Qamar $\mathrm{S}$, Niazi S, Syed SZ, Yusuf AW, Yusuf NW. Clinicopathological study of Papanicolau (Pap) smears for diagnosis of cervical infections. Diagn Cytopathol. 2012;40(1):3541. doi: 10.1002/dc.21498, PMID 20949462.

8. Barouti E, Farzaneh F, Sene AA, Tajik $Z$, Jafari B. The pathogenic microorganisms in Papanicolau vaginal smears and correlation with inflammation. J Family Reprod Health. 2013;7(1):23-7. PMID 24971098. 
9. Guduco $N$, Gonene $G$, Isci $H$, Yigiter $A B$, Bassullu N, Dunder I. Clinical importance of detection of Bacterial vaginosis, Trichomonas vaginalis, Candida albicans and Actinomyces in Papanicolau smears. Clin Exp Obstet Gynecol. 2012;39:333-36.

10. Dalie F, Watchler B, L'oliver C, Holland G, Bannert G, Wilson D, et al. Cellular interaction of Candida albicans with human oral epithelial cells and enterocytes. Cell Microviol. 2010;12:248-71.

11. Mayer FL, Wilson D, Hube B. Candida albicans: Pathogenecity mechanisms. Virulence. 2013;4(2):119-28. doi: 10.4161/ viru.22913, PMID 23302789.

12. Wohlmaster D, Vianna DRB, Heifer VE, Gimervas F, Consolan MEL, Barcello RB, et al. association of human papillomavirus infection and Chlamydia trachomatis with intraepithelial alterations in cervical samples. Mem Institut OswalwReodeJanso; 2016. p. $11(2): 186$.

13. Masand DL, Patel J, Gupta S. Utility of microbiological profile of symptomatic vaginal discharge in rural women of reproductive age group. J Clin Diagn Res. 2015;9(3):QC047. doi: $10.7860 / J C D R / 2015 / 12161.5623$, PMID 25954668. 